\title{
Leaching of pyrite in cupric chloride solution
}

\author{
Heini Elomaa ${ }^{1, a}$, Mari Lundström ${ }^{1}$ \\ ${ }^{1}$ Aalto University, School of Chemical Technology, Department of Materials Science and Engineering, P.O. Box \\ 16200, FI-00076 AALTO, Finland
}

\begin{abstract}
Pyrite $\left(\mathrm{FeS}_{2}\right)$ is the most abundant sulphide mineral in the world and may contain significant amounts of gold locked in its structure. Traditionally, pyrite has to be oxidized in order to break down the mineral matrix for better gold liberation by e.g. roasting, pressure leaching and bioleaching [1]. Due to environmental and health concerns, as well as public opinion, alternative methods are developed to replace gold cyanide leaching, which has been the preferred gold leaching process. Gold is known to form a stable complex with chloride as $\left[\mathrm{AuCl}_{4}\right]^{-}$or $\left[\mathrm{AuCl}_{2}\right]^{-}$. In chloride leaching of pyrite in the presence of $\left[\mathrm{Cu}^{2+}\right]$ which acts as a catalyst/oxidant, the pyrite structure can be simultaneously broken down and the gold dissolves into a solution from which it can be later recovered $[2,3]$. In this study, dissolution of the pyrite concentrate in cupric chloride solutions was investigated. The effect of cupric ion concentration $(16,32 \mathrm{~g} / \mathrm{L})$, temperature, $\left(60,75,90^{\circ} \mathrm{C}\right)$, chloride ion concentration $(50,150$ $\mathrm{g} / \mathrm{L}), \mathrm{pH}(1,1.5)$ and mixed chloride-bromide ion concentration $(75+75 \mathrm{~g} / \mathrm{L})$ on pyrite dissolution were studied during 6 hour batch leaching experiments. Redox potentials between $0.495-0.511 \mathrm{~V}$ vs. $\mathrm{Ag} / \mathrm{AgCl}$ resulted in pyrite dissolution of $31-34 \%$, whereas redox potentials between $0.523-0.573 \mathrm{~V}$ vs. $\mathrm{Ag} / \mathrm{AgCl}$ resulted in $45-68 \%$ pyrite dissolution.
\end{abstract}

\section{References}

1. O. Marsden and C. I. House, The Chemistry of gold extraction, 2nd edit. (Colorado, 2006)

2. V. Miettinen, M. Haapalainen, R. Ahtiainen, J. Karonen, in Proceedings of ALTA Metallurgical Seirvices, 187 (2013)

3. M. Lundström, R. Ahtiainen, T. Haakana and J. O'Callaghan, in Proceedings of ALTA Metallurgical Services, 16 (2014)

\footnotetext{
${ }^{\text {a }}$ Corresponding author: heini.elomaa@aalto.fi
} 